\title{
Trunk Appearance Perception Scale (TAPS) discrepancy between scoliosis children and their parents influence the SRS-22 secore
}

\author{
M Rigo*, E D’agata, M Jelacic \\ From 8th International Conference on Conservative Management of Spinal Deformities and SOSORT 2011 \\ Annual Meeting \\ Barcelona, Spain. 19-21 May 2011
}

\section{Background}

The Trunk Appearance Perception Scale (TAPS) is a valid instrument to assess self perception of trunk deformity [1]. The SRS-22 has been widely used to measure Health Related Quality of Life in scoliosis population but it is not clear which factors can influence its final score [2-4].

\section{Study}

Trunk deformity can be perceived differently by children and parents $[5,6]$. The aim of this study was to check whether different perception of the trunk deformity between patients and parents is a factor influencing the SRS-22 or not.

\section{Materials and methods}

Prospective study including 71 (62 F, 9 M) patients with idiopathic scoliosis (treated and non treated), attending the clinic with their parents. Mean age $17 \mathrm{y} \pm 5.7$. Mean Cobb angle $37^{\circ} \pm 15^{\circ}$. All patients completed the SRS-22 and the TAPS. Parents completed the TAPS assessing trunk deformity of their children. A coeficient of discrepancy (TAPS-CD) was defined. Statistical analysis was performed by using SPSS to compare TAPS, TAPS-CD and SRS-22.

\section{Results}

Results showed a negative correlation between TPAS-CD and the total SRS-22 ( $\mathrm{p}<.05)$ and treatment satisfaction $(\mathrm{p}<.05)$. A significant positive correlation was found between patients TAPS, self-image and pain and between parents TAPS, function and treatment satisfaction in the
SRS-22. Two groups were created according to the SRS22 score. Patients with higher score in the SRS-22 showed a higher TAPS-CD $(\mathrm{P}<.05)$.

\section{Conclusion}

Discrepancy in Trunk Deformity Perception between children and parents influence the SRS-22 of the children. Patients' perception and parents' perception of trunk deformity influence the SRS-22 differentely.

Published: 27 January 2012

\section{References}

1. Bagó J, Sánchez-Raya J, Pérez-Grueso FJ Sánchez, Climent JM: The Trink Appearance Perception Scale (TAPS): A new tool to evaluate subjective impression of trunk deformity in patients with idiopathic scoliosis. Scoliosis 2010, 5:6.

2. Asher M, Lai SM, Burton D, Manna B: The influence of spinal and trunk deformity on preoperative idiopathic scoliosis patient's health-related quality of life questionnaire responses. Spine 2004, 29:861-888.

3. Bago J, Climent JM, Ey A, Perez-Grueso FJ, Izquierdo E: The Spanish version of the SRS-22 patient questionnaire for idiopathic scoliosis: transcultural adaptation and reliability analysis. Spine 2004, 29(15):1676-1680.

4. Climent JM, Bagó J, Sánchez J, et al: Validity of the Spanish version of the Scoliosis Reseacrh Society -22 (SRS-22) Patient Questionnaire. Spine 2005, 30:705-709.

5. Rinella A, Lenke L, Peelle M, Edwards C, Bridwell KH, Sides B: Comparison of SRS questionnaire results submitted by both parents and patients in the operative treatment of isiopathic scoliosis. Spine 2004, 29(3):303-310.

6. Smith PL, Donaldson S, Hedden D, Alman B, Howard A, Stephens D, et al: Parents' and patients' perception of postoperative appearance in adolescent idiopathic scoliosis. Spine 2006, 31(29):2367-2347.

doi:10.1186/1748-7161-7-S1-O3

Cite this article as: Rigo et al:: Trunk Appearance Perception Scale (TAPS) discrepancy between scoliosis children and their parents influence the SRS-22 secore. Scoliosis 2012 7(Suppl 1):O3. 